\title{
Is communication guidance mistaken? Qualitative study of parent-oncologist communication in childhood cancer
}

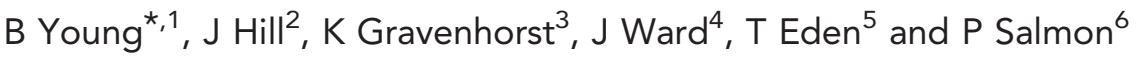 \\ ${ }^{1}$ Department of Psychological Sciences, University of Liverpool, Whelan Building, Brownlow Hill, Liverpool L69 3GB, UK; ${ }^{2}$ Child \\ Psychiatry Research Group, University of Manchester, University Place, Manchester M13 9PL, UK; ${ }^{3}$ Department of Psychological \\ Sciences, University of Liverpool, Waterhouse Building, Liverpool L69 3GB, UK; ${ }^{4}$ Wrexham County Borough Council, Crown \\ Buildings, 31 Chester Street, Wrexham LL13 8BG, UK; ${ }^{5}$ Adademic Unit of Paediatric and Adololescent Oncology, University of \\ Manchester, Manchester M20 4BX, UK and ' Department of Psychological Sciences, University of Liverpool, Whelan Building, \\ Liverpool L69 3GB, UK
}

Background: Guidance encourages oncologists to engage patients and relatives in discussing the emotions that accompany cancer diagnosis and treatment. We investigated the perspectives of parents of children with leukaemia on the role of paediatric oncologists in such discussion.

Methods: Qualitative study comprising 33 audio-recorded parent-oncologist consultations and semi-structured interviews with 67 parents during the year following diagnosis.

Results: Consultations soon after the diagnosis were largely devoid of overt discussion of parental emotion. Interviewed parents did not describe a need for such discussion. They spoke of being comforted by oncologists' clinical focus, by the biomedical information they provided and by their calmness and constancy. When we explicitly asked parents 1 year later about the oncologists' role in emotional support, they overwhelmingly told us that they did not want to discuss their feelings with oncologists. They wanted to preserve the oncologists' focus on their child's clinical care, deprecated anything that diverted from this and spoke of the value of boundaries in the parent-oncologist relationship.

Conclusion: Parents were usually comforted by oncologists, but this was not achieved in the way suggested by communication guidance. Communication guidance would benefit from an enhanced understanding of how emotional support is experienced by those who rely on it.

Much research and training in clinical communication has been guided by a belief that oncologists have a role in helping patients with their fears, and that this role includes supporting patients in expressing their feelings during consultations and responding appropriately to such overt emotionality (Maguire, 1999; Epstein and Street, 2007; Girgis et al, 2009; Bonito et al, 2013). Oncologists have therefore been encouraged to elicit and overtly discuss the emotional concerns of patients and their families (Stiefel et al, 2010; Tulsky et al, 2011). Nevertheless, studies of patient-oncologist consultations indicate that such communication is the exception rather than the rule (Pollak et al, 2007; Hack et al, 2010; Rodriguez et al, 2010), prompting calls for more communication training for oncologists. However, beyond its possible role in identifying those patients experiencing pathological distress, evidence that patients find it helpful to discuss their emotions with oncologists is inconclusive (Lobb et al, 2004; Uitterhoeve et al, 2010; Tulsky et al, 2011; Johnson et al, 2013). Moreover, theory that explains how explicit emotionality in medical consultations

*Correspondence: Professor B Young; E-mail byoung@liv.ac.uk

Received 20 March 2013; revised 27 June 2013; accepted 1 July 2013; published online 30 July 2013

(c) 2013 Cancer Research UK. All rights reserved 0007-0920/13 
helps patients to regulate their fears is lacking (Pedersen, 2009; Hack et al, 2010). If guidance and training are to enhance care from the perspective of patients and their families, the role of oncologists in the emotional care of patients and their families needs to be better understood.

Our study addressed this objective. Its focus was parentoncologist communication in the care of pre-adolescent children undergoing curative treatment for acute lymphoblastic leukaemia (ALL). Treatment for ALL has improved dramatically in the last 30-40 years. Over $85 \%$ of children now survive for 5 years (Vora et al, 2013) and most can be regarded as cured. Nevertheless, the treatment is arduous and cure is not guaranteed. Parents live with the fear that their child might die from the illness or be harmed by the treatment, fears that remain with them over the 2- to 3-year treatment period and beyond (Wakefield et al, 2011). In this profoundly emotional context, we investigated the role of paediatric oncologists in the emotional care of parents with the aim of informing communication guidance and training.

\section{MATERIALS AND METHODS}

Design and sampling. We designed this qualitative study, RAPPORT, to take account of the multi-dimensional and subjective nature of interpersonal communication (Salmon and Young, 2011). In particular, knowing what people have said to one another (i.e., the appearance or form of a conversation) may reveal little of how people actually experience a conversation. The reverse is also true - knowing how people experience a conversation may give little indication of what was actually said. Studies that do not investigate and compare both aspects of communication limit our understanding of clinical relationships and communication (Beckett et al, 2009; Salmon et al, 2011). Therefore, we collected audio-recordings of parent-oncologist consultations, and a researcher subsequently conducted semi-structured interviews with parents about what the consultations meant to them. We collected data at three time points corresponding to 'early' ( $\sim 6-8$ weeks), 'interim' ( $\sim 6$ months) and 'late' ( $\sim 12$ months) postdiagnostic phases. Most parents entered the study at the early phase and remained for the subsequent phases, but some entered at the interim and late phases. Therefore, our study followed most participants longitudinally. Parents were eligible if their child was aged 1-12 years, had been diagnosed with ALL and clinical teams did not judge participation inappropriate because of clinical complications or psychosocial difficulties. To minimise the possible exclusion of parents whose relationships with oncologists were strained, we regularly reviewed with the paediatric centres the reasons why families were not approached. Sampling aimed for maximum diversity, paralleled the analysis and stopped when additional data ceased to contribute to the analysis.

Although we collected consultation and interview data at all three phases, in this paper we focus mainly on the early-phase consultations and parent interviews because we expected parents' fears to be most intense and their need for help with these fears to be most prominent at this time. We also included the subsequent parent interviews, particularly the late-phase interviews (conducted 1 year after diagnosis). For these late-phase interviews, we developed questions to explore parents' responses to our emergent analyses of the earlier data (see Box 1 for excerpts from the latephase interview topic guide). In this way we were able to 'test' our interpretations with parents.

Recruitment and procedure. Data were collected between 2007 and 2009. We held initial discussions with treatment centres about the study and visited all participating centres to explain the study before recruitment of parents commenced. Oncologists and research nurses initially approached parents about the study and
Box 1. Example excerpts from late-phase interview topic guide

\section{Most recent audio-recorded consultation}

- Can you tell me about what was on your mind before that last consultation? Were you able to ask about those things? Is there anything that sticks out in your mind about that consultation?

- I have listened to the recording of the consultation. Do you mind if I ask you about a few of the things that I noticed...?

\section{Changing nature of consultations}

- I've noticed that many of the consultations seem to be shorter than earlier during treatment. Is this something that you've noticed? How do you feel about the amount of time the consultant/staff have for you now?

- Has there been any change in the sorts of things that are talked about in consultations?

- Some of the consultations we've listened to have at times been quite light-hearted in tone. Have any of your consultations been like that? I've wondered how this might feel for parents? Is it ever hard to voice what's really on your mind?

- When it comes down to it, all these consultations are about saving [name of child]'s life. But we've noticed that parents' fears are often not discussed. How do you feel about the sorts of things discussed in the consultations?

- Have you ever wanted to talk about these issues but felt unable to do so? What has stopped you from talking about them? Is there anyone else who you can talk to?

\section{Relationships}

- How would you describe the relationship you have with Dr [name of consultant] now?

- Have there been times when you've felt uneasy about any aspect of the care you've had as a family? Can you tell me a little bit about that?

- Have you ever had to be quite firm with the staff or put your foot down about anything? What happened?

\section{Fears and emotions}

- Some parents say they give the impression of being okay on the outside, but deep down on the inside they feel real turmoil. Others describe feeling bewildered or angry at times. Have you ever felt this way?

- Have you ever discussed these feelings with anyone? Could you imagine mentioning them to Dr [name of consultant]? What about to the nurses?

- In what ways do you think that consultants can help parents? Do you think there are any ways they help parents emotionally? And what about nurses?

gave them written information. Qualitative researchers (JW and KG) subsequently explained the study in detail, explaining their independence from the clinical teams and that all study information would be kept confidential. Parents who agreed to participate gave written consent. Oncologists, some of whom had approached parents about the study, audio-recorded one routine consultation per family at each phase. For the early phase consultations that are the focus of this paper, oncologists usually audio-recorded the first consultation after parental consent had been obtained. Face-to-face semi-structured interviews after each consultation explored parents' experiences of communication, consultations, relationships with staff, and the impact of the illness and treatment on themselves and their child. We asked to interview mothers and fathers separately, but accommodated the preferences of parents who wished to be interviewed together. 
Researchers listened to the audio-recorded consultations before the interviews to inform their questions. The use of topic guides helped to ensure exploration of core topics, although we adapted these for each study phase to allow exploration of emergent analyses as described above. Digitally audio-recorded consultations and interviews were transcribed, checked and anonymised. Transcription recorded all major dysfluencies, emphases and pauses; punctuation was added to aid interpretation. For the consultations we also noted overlapping speech.

Analysis. Analysis was informed by the constant comparative approach and procedures to support quality in qualitative research (Strauss and Corbin, 1998; Kuper et al, 2008). Specifically, we used previously described methods (Salmon et al, 2011) to link and compare two strands of analysis. This comprised (i) a cross-case strand where we analysed data on a consultation-by-consultation basis separately from an analysis on an interview-by-interview basis and (ii) a within-case strand where we analysed consultation and interview data together on a parent-by-parent basis (providing both consultation and interview data were available for a parent). We analysed consultation transcripts for evidence of overt discussion of parental fears and emotional concerns. We analysed interview transcripts for evidence of how parents experienced the relationship and communication with oncologists. Our analyses were interpretive and considered both latent and manifest aspects of the data; for example, we considered what parents gave little emphasis to in their interviews as well as what they emphasised. To ensure a contextualised analysis, we referred to transcripts as a whole as well as to particular data segments. As noted above, we also used a type of respondent validation to 'test' the validity of our interpretations from the perspective of parents. BY led the analysis but all authors were closely involved, reading several sets of transcripts, reviewing detailed reports of the analysis, and participating in extensive discussions to develop and scrutinise the analysis. This investigator triangulation, combined with discussion of the findings with members of the study steering group, comprising oncologists and parent representatives (whose children had been previously treated for cancer), allowed corroboration of the findings from multiple perspectives. Although the analysis was grounded in the data, we also explored links between our findings and theoretical ideas in the literature and the potential of the analysis to inform practice (Reeves et al, 2008).

To evidence our interpretations we present illustrative extracts from our data. Identification codes indicate centres (A-F), oncologists $(\mathrm{o})$, mothers $(\mathrm{m})$ and fathers $(\mathrm{f})$; $r$ indicates researcher's speech. For consultation extracts, [(text)] indicates overlapping speech.

\section{RESULTS}

Sample. Nine principal paediatric oncology/haematology treatment centres in different regions of the United Kingdom were formally approached to participate and six enrolled. Of the three non-participating centres, two declined and one was not pursued because the target number of centres had been reached. Of oncologists with overall responsibility for patients with ALL at participating centres, three either did not identify suitable patients or declined permission for families of patients in their care to be approached about the study (Table 1). Sixty-seven parents (40 mothers, 27 fathers) from 43 families participated. Thirty-four families entered the study in the early-post-diagnosis phase, whereas eight joined at the interim and late phases, respectively. Table 1 shows the numbers of families cared for across the six centres during the period when the study was open at the early phase. It also shows, by study phase, the numbers approached, consented and participating in different study elements that we report in this paper. The 33 audio-recorded consultations took place a median of 6 weeks after diagnosis (range 2-13), lasted a

Table 1. Families approached, consented and interviewed and interview timing, by study phase

\begin{tabular}{|c|c|c|c|c|c|c|c|c|c|c|}
\hline \multirow[b]{2}{*}{$\begin{array}{l}\text { Study } \\
\text { phase }\end{array}$} & \multirow[b]{2}{*}{$\begin{array}{l}\text { Families } \\
\text { (N) } \\
\text { under } \\
\text { care of } \\
\text { centres }\end{array}$} & \multirow[b]{2}{*}{$\begin{array}{l}\text { Appro- } \\
\text { ached } \\
(\mathbf{N})\end{array}$} & \multirow[b]{2}{*}{$\begin{array}{l}\text { Con- } \\
\text { sented } \\
(N)\end{array}$} & \multicolumn{3}{|c|}{$\begin{array}{c}\text { Early post-diagnosis } \\
\text { phase }\end{array}$} & \multicolumn{2}{|c|}{$\begin{array}{c}\text { Interim post-diagnosis } \\
\text { phase }\end{array}$} & \multicolumn{2}{|c|}{$\begin{array}{l}\text { Late post-diagnosis } \\
\text { phase }\end{array}$} \\
\hline & & & & $\begin{array}{l}\text { Audio- } \\
\text { recorded } \\
\text { consultations } \\
\text { (N) }\end{array}$ & $\begin{array}{l}\text { Families- } \\
\text { inter- } \\
\text { viewed } \\
(\boldsymbol{N})\end{array}$ & $\begin{array}{l}\text { Median } \\
\text { interview } \\
\text { timing } \\
\text { (weeks) } \\
\text { after } \\
\text { child's } \\
\text { first } \\
\text { hospital } \\
\text { admission } \\
\text { (range) }\end{array}$ & $\begin{array}{l}\text { Families- } \\
\text { Interviewed } \\
(\boldsymbol{N})\end{array}$ & $\begin{array}{l}\text { Median } \\
\text { interview } \\
\text { timing } \\
\text { (weeks) } \\
\text { after } \\
\text { child's } \\
\text { first } \\
\text { hospital } \\
\text { admission } \\
\text { (range) }\end{array}$ & $\begin{array}{c}\text { Families- } \\
\text { interviewed } \\
\text { (N) }\end{array}$ & $\begin{array}{c}\text { Median } \\
\text { interview } \\
\text { timing } \\
\text { (weeks) } \\
\text { after } \\
\text { child's } \\
\text { first } \\
\text { hospital } \\
\text { admission } \\
\text { (range) }\end{array}$ \\
\hline Early & $71^{a}$ & 53 & 39 & 33 & $\begin{array}{c}34^{\mathrm{b}} \\
\text { (31 mothers, } \\
22 \text { fathers) }\end{array}$ & $8(4-20)$ & $\begin{array}{l}34 \text { (31 mothers, } \\
16 \text { fathers) }\end{array}$ & $30(23-43)$ & $\begin{array}{l}33 \text { (31 mothers, } \\
17 \text { fathers) }\end{array}$ & $60(51-106)$ \\
\hline Interim & NA & 5 & 4 & NA & NA & NA & $\begin{array}{c}4 \text { (4 mothers, } 4 \\
\text { fathers) }\end{array}$ & $28(18-32)$ & $\begin{array}{c}4 \text { (4 mothers, } \\
4 \text { fathers) }\end{array}$ & 62 (54-75) \\
\hline Late & NA & 9 & 5 & NA & NA & NA & NA & NA & $\begin{array}{l}4^{c} \text { (4 mothers, } \\
1 \text { father) }\end{array}$ & $58(50-67)$ \\
\hline \multicolumn{11}{|c|}{$\begin{array}{l}\text { a } 18 \text { families were not approached about the study at the early post-diagnosis phase. Twelve were judged ineligible by the treating clinical teams, who reported that three children had medica } \\
\text { complications and nine families had severe psychosocial difficulties. The remaining six non-approached families were in the care of three oncologists (with overall responsibility for patients with } \\
\text { ALL) who either did not identify suitable patients or declined permission for families of children under their care to be invited to participate. } \\
\text { b Four families withdrew before interview and one family did not want to be interviewed at the early post-diagnosis phase but remained in the study and participated in subsequent data collection. } \\
\text { c One family was withdrawn by the clinical team before interview because statutory child safeguarding proceedings had been initiated. }\end{array}$} \\
\hline
\end{tabular}


median of $23 \mathrm{~min}$ (range 6-70) and were with 13 oncologists. Mothers were present for all 33 consultations, fathers for 23 and children for 24. Across all phases, interviews lasted $\sim 90 \mathrm{~min}$ (range 20-180); all except nine were with mothers and fathers separately and all took place in parents' homes, except for 23 that took place in hospital and four in other places of parents' choosing. Children's median age was 4 years at study entry. The sample was socio-economically diverse. Nine were single parent families. According to the Townsend Deprivation Index (Townsend et al, 1988), 12 families resided in the fifth most deprived areas of the United Kingdom and 12 in the least deprived fifth; the rest were distributed across the remaining quintiles. However, only two families were from an ethnic minority.

Overt emotion was minimal in consultations yet parents were comforted. In their interviews parents readily described their emotions as 'raw' (Af5) at diagnosis and the news of their child's illness as 'absolutely terrifying' (Am9). They spoke of their fear that their child would not survive, 'all you think of is, they're going to die' (Dm6), and explained that their fears never left them, 'always at the back of your mind' (Af5). Despite the intensity of parents' fears, the parent-oncologist consultations recorded in the weeks after diagnosis were mostly conducted with minimal explicit discussion of emotion by either parents or oncologists. Nevertheless, parents described how consultations with oncologists were 'very comforting [...] I just thought phew, you know, um, after such a shock that our lives are in their hands at the moment and I felt quite happy at that' (Fm2).

Several consultations involved oncologists giving parents the results of bone marrow and minimal residual disease (MRD) tests that indicated that a child was in a 'high risk' group. Such children were also eligible for a randomised clinical trial comparing the standard treatment with a more intensive treatment. When interviewed, parents described these consultations as 'a shock' and like hearing 'the initial diagnosis' (Af8). Box 2 illustrates such a consultation (Fmf5). It involved a long and complicated discussion about the test result, the implications for the child's treatment and prognosis, and the clinical trial. Biomedical rather than emotional issues dominated. The oncologist referred several times to his feelings about giving the news but there was no explicit discussion of the parents' emotions. Despite this, in their interviews the father remarked on how he had been reassured by the consultation and by the oncologist's 'straight' way of explaining the results, while the mother appreciated the oncologist's 'calm' and 'gentle' approach.

\section{Ways that parents found oncologists comforting}

Be expert. In their interviews, parents recounted how oncologists had helped them to feel 'very comforted' at the time of diagnosis (Fm2-Box 3). They particularly pointed to the importance in this process of oncologists' 'fact based' (Af5) explanations about the efficacy of treatment and about the steps that oncologists were taking to care for their child. Some parents even spoke of oncologists as 'not having the emotion that we have' and described this as a 'benefit' (Ff5). Although the comforting effect of information about treatment may seem unremarkable, it indicated how oncologists' instrumental expertise could feel intensely emotional for parents. Conversely, a father spoke of his dissatisfaction with the well-delivered but inexpert and unreassuring explanation of leukaemia that he had received at the nonspecialist centre where his child was initially diagnosed, 'I almost got the impression there was more care taken over how we were told than what we were told' (Af8), adding that the explanation of leukaemia at the non-specialist centre had been 'very light $[. .$.$] on$ the fact that [...] the prognosis is not the same as it was twenty years ago' (Af8).
Box 2. Explicit discussion of parents' emotions was absent during consultations with oncologists, yet in subsequent interviews parents remarked on how consultations had comforted them

This excerpt is from a results consultation with an oncologist (02) and a mother and father (Fm5; Ff5) that lasted about $35 \mathrm{~min}$. The oncologist and parents initially discussed the child's well-being since the previous clinic visit. Seven minutes into the consultation, the oncologist started to discuss the MRD test result:

02 the result I got back from her is that, that her leukaemia is, is responding a bit on the slow side

m5 really?

o2 yeah so that's why erm erm we would have to talk about just a little bit erm and as well- and she would qualify for this randomisation, which is $[\ldots]$

m5 [(so does that)] sorry, so does that make her chances of relapse great, greater?

02 a little bit yes it's difficult to quantify this because it's not that her leukaemia isn't responding to the treatment

m5 mmm

02 and because we saw $[\ldots]$ a response in the bone marrow after four weeks $[\ldots]$ I mean still even in her situation that the vast majority of children will never develop erm a relapse $[\ldots]$ but still remain erm in remission and the leukaemia wouldn't recur

[Oncologist discusses the difficulties of drawing conclusions about survival for individual children from population-level statistics while explaining the change in prognosis for the child and some details of the trial]

o2 I'm sorry I would like to have, would like to have given you a bit more positive erm news today $[\ldots]$ I know that she has had quite a difficult [...] difficult ride through the last couple of weeks

[Oncologist offers to explain treatment regimens $\mathrm{A}$ and $\mathrm{C}$ in more detail and very briefly leaves room to get the charts. On return he explains regimens $\mathrm{A}$ and $\mathrm{C}$ and the trial randomisation; he also responds to the parents' questions about the side effects of regimen $\mathrm{C}$ and the trial. The parents then ask about what the results mean for their daughter's risk of relapse]

02 that's a hard question

m5 I don't know if I want to know [said quietly]

o2 I think that's the important question I completely agree

[Parents and oncologist clarify the question and oncologist describes the risks of relapse for children with MRD results like their daughter's]

o2 [...] so 7 out of 10 children in that group will never relapse 3 out of 10 children in that group will go on to get a relapse of their leukaemia and this is higher than the overall group, the overall group we say that about 8 out of 10 children erm with childhood leukaemia will never relapse [(but will stay in remission)]

m5 [(it's not a big difference)] is it

o2 it's not a huge difference [(it's it's it's)]

m5 [(but it is a difference)]

02 it's a difference

[Parents and oncologist continue to discuss the risk of relapse and then the trial]

o2 [...] obviously I would be much more happy if I'd be telling you 'oh she responds super to treatment' but [...] the differences between the group who's not MRD high risk and her erm from what we know at the moment isn't is isn't huge [...] we are in- it's still a situation that erm the majority of children in her situation will never develop a leukaemia

In his subsequent interview the father explained that he was reassured by the oncologist's 'straight' approach: 'It was a very difficult consultation erm [...] and he did it without a degree of emotion, which from my point of view I appreciate, because if someone was apologetic and this, that and everything, you start to think a lot of things are wrong. And he was very straight' (Ff5). In her interview the mother spoke of how she had valued the oncologist's 'very calm' and 'gentle' (Fm5) approach 
Box 3. Role of oncologists' expertise, calmness and constancy in comforting parents

\section{Expertise}

'He, he seemed very confident in what he was doing, in his knowledge [...] you came away thinking, 'We seem to have somebody here who knows what he's doing' $[\ldots]$ he just sort of instilled us with confidence' Df1

'Your whole world is like a storm, God, what's going to happen, what's going to happen to my kid? Then you hear somebody sit down so rationally and talk to you so calm. You feel that, you know, it's not as bad as people think it is. And particularly when they give you information on treatment' Bm4

\section{Calmness}

'He's just a very calming person [...] I want to say emotionless but that's not the right word $[\ldots]$ he's just calm, nothing seems to shock him, $[\ldots]$ you can ask him questions $[\ldots]$ and appears very matter of fact $[\ldots]$ he is somebody that I think you could ask, ask anything of' $\mathrm{Cm} 4$

'He was great, um, 'cause he's so calm and he's so, he sounds so knowledgeable and he sits on the bed and he properly looks you in the eye and I really, really liked him straightaway. I just, I felt, I really trusted him' Af10

\section{Constancy}

'He came and sat with us for ages and he came, visited I, I don't know how many times, quite a few times during that first 24-48 h [...] it made us, feel that she was, she's the most important thing [...] I think that was really comforting [...] it seemed to us at the time that it was, she was the only one which [mattered]

[...] and it made us feel that, we were very, very important' Dm1

The importance of constancy was demonstrated by its absence too, as indicated by the remarks that parents made about 'missing' the oncologist: 'We've not seen him [oncologist] for a while though. We've not seen him for quite, I would like to see him [...] it would be nice just to see him' Df14

Parents also valued oncologists' constancy in their interaction with their child:

'You'll draw comfort [...] from the small things [...] stop and say 'hi [to my child],' the parents will look at each other and think great they know [his] name, so he's obviously [they're] talking about him. That's what you draw comfort from' Af5

'He's lovely with [my child] [...] when he's examining her tummy, or he always finishes off with a tickle $[\ldots]$ things like that, make a difference, to me $[\ldots]$ knowing that he's like that with her' Dm1

Be calm. The importance parents placed on instrumentality did not mean they were content for oncologists to be remote or to appear uncaring: 'you don't want somebody who is totally isolated, who just comes in and goes 'this is what you're doing, go away'. Doesn't work like that' (Df9). Parents were clear that the way oncologists interacted with them was important, and, indeed, some placed considerable emphasis on how this comforted them. Parents repeatedly commented on the oncologists' 'calm' manner (e.g., $\mathrm{Bm} 4)$ and gave this as a reason for experiencing oncologists as comforting and for liking and trusting them (Box 3). This also extended to oncologists' calmness in interacting with children: ' consultant is] lovely [...] talks lovely to the kids, talks softly, try and calm the kids down [...] that's nice in itself because they're panicking and they calm the children down' (Af6).

Be constant. Parents spoke repeatedly of the ways that oncologists interacted or of the 'small things' (Af5) that oncologists did that they found comforting (Box 3). We refer to these behaviours collectively as 'constancy' behaviours because they indicated oncologists' dependability and availability from parents' perspective. The particular behaviours involved were diverse. For example, parents remarked on how oncologists' interactions with them, such as stopping to say 'hello' (Cf2) when passing in a corridor or taking 'time out' (Dm8) 'to have a conversation' (Am9) during consultations, helped parents to feel more than 'just another number' (Df9). Similarly, a mother remarked on how she valued an oncologist's steadfastness in responding to her husband's questions: 'He kept asking the same question [...] but she [the oncologist] never, ever wavered. She just kept explaining it to him [...] over and over until he got it [...] I thought that was really nice' (Am9). Other parents spoke of the importance of contact with the oncologist and described how they missed their oncologist when she/he had not been available, 'I looked forward to his visit every morning [...] if he wasn't on [it was] 'tut it's somebody else' (Dm3), and almost all parents spoke of how they were comforted by oncologists' constancy in interactions with their child (Box 3). Although parents were comforted by oncologists' constancy, none of these behaviours involved oncologists engaging parents in overtly emotional discussion.

Why parents did not want explicit emotionality. Many parents spoke at length about the various ways in which they had experienced oncologists as comforting in the absence of emotional discussion. We explored this further when we interviewed parents a year after diagnosis. Although they were still fearful at this point, describing having 'always that thing in the back of your head' $(\mathrm{Bm} 8)$, parents spoke repeatedly and in some cases emphatically of how they did not want to discuss their emotions with oncologists (Box 4). One mother indicated that she felt cared for emotionally without explicit emotional talk: 'you can sometimes feel that [caring] without somebody saying sit down and pour your heart out to me. I think just their whole manner, the way they are' (Dm6). Others explained that they wanted to preserve the oncologist's focus and expertise for their child: 'I don't think you really need to be discussing your sort of related problems with the consultants [...] leave them to curing children' (Dm2). Parents also alluded to the value of boundaries in their relationships with oncologists and pointed to people-other professionals (particularly specialist community nurses) or personal contacts-with whom they felt it more appropriate to discuss their emotions. Parents felt oncologists could 'signpost' (Cm2) them to professional sources of emotional support. Nevertheless, from their perspective it was not an oncologist's role to routinely engage parents in emotional discussions. Only two parents spoke of wanting to discuss their emotions with oncologists (Box 5). Of these, one parent (Dm3) also spoke of her ambivalence about the oncologist's role in discussing parental emotions. Therefore, her account might be more appropriately regarded as a 'boundary' rather than an 'outlier' case. The other parent (Af8) had a child who had experienced many side effects, and he was dissatisfied with many aspects of his child's care.

\section{DISCUSSION}

Oncologists were usually a source of comfort for parents, but comfort was not accomplished in the way communication guidance emphasises. Most parents did not want overtly emotional discussions with oncologists. Although patients in previous studies have expressed similar sentiments (Thomsen et al, 2007; Goldman et al, 2009), our longitudinal design enabled us to explore parents' reasons. Parents felt that oncologists did address their fears but mainly did so instrumentally, through their expert clinical care and by discussing the treatment. They believed that going beyond this to talk overtly about their emotions with oncologists was unnecessary, inappropriate or unhelpful, and they spoke of the value of having boundaries in their relationships with oncologists. Given the pervasive and intense nature of parents' fears, their reluctance to discuss their feelings with oncologists may seem counterintuitive. However, parents did not perceive oncologists as in any way invalidating their fears by not exploring them. Rather 
Box 4. Parents did not want to have overtly emotional discussions with oncologists

\begin{tabular}{|c|c|}
\hline m3 & $\begin{array}{l}\text { 'It's just the most awful thing to have to go through }[\ldots] \text { it's not like } \\
\text { having lost a parent }[\ldots] \text { it's not like those kind of things that affect } \\
\text { other people. It's just the most horrendous thing, having a child with } \\
\text { such a life threatening illness, it's just horrendous }[\ldots] \text { I suppose if } \\
\text { we wanted to there would be people that we could go and talk to } \\
\text { really }[\ldots]\end{array}$ \\
\hline$r$ & Do you think one of those people should really be the consultant $[\ldots]$ ? \\
\hline$m 3$ & No. \\
\hline f3 & No. \\
\hline$m 3$ & No, definitely not. No. It's not. \\
\hline$f 3$ & It's not their department, is it? \\
\hline m3 & $\begin{array}{l}\text { It's not }[\ldots] \text { it isn't their job, it isn't their job to, it isn't at all and it } \\
\text { shouldn't ever be' Cmf3 }\end{array}$ \\
\hline
\end{tabular}

'The consultant's job from where I see it is to be on the ball with the kids and their treatment [...] they've got an important job that they need to do and I think that you've got to draw the line somewhere [...] I don't think [the emotional care is] really what the consultants need to be doing' Dm6

Parents spoke of the importance of boundaries in their relationships with oncologists

'You don't want to be their best friend [...] It's being appropriate in a professional and clinical way isn't it? [...] I think they do that [...] in a personable way [...] I don't want them to be, they don't need to be my best friend' $\mathrm{Cm} 2$

'I don't want to be the best friend of the consultant I just want them to be very good at what they do' Af9

Parents mostly preferred practitioners such as nurses, counsellors and social workers, or family, friends and other parents of children with cancer for providing overt emotional support

'The nurses were fantastic [...] there were times when I was in a real state and they spent time $[\ldots]$ but that's not their main job [...] their main aim is the children and they were very much there for the parents which I think is remarkable [...] the nurses kind of can take over a lot of the information [...] and the emotional stuff' Dm6

'There's outside agencies who'll give you the support [...] Like the Macmillan nurse $[\ldots]$ they also give us a, um, somebody to talk to [...] it's nice just, just really to talk to a stranger [...] who knows about leukaemia' Df11

Box 5. "Outlier" cases: parents who wanted to discuss their feelings with oncologists

\section{Case one: Dm3}

This mother wanted more emotional support from the oncologist, 'at times yes, you do want more', yet she also remarked that the oncologist could not be an 'emotional crux for parents, he's there to cure your child' and implied that it was unrealistic to expect otherwise: 'I don't think they [oncologists] can give any more [...] how could they spread themselves that thin?' Therefore, this parent might, ultimately, be more appropriately regarded as a 'boundary' case rather than an outlier.

\section{Case two: Af8}

This father described several shortcomings regarding the care of his daughter, who was on the most intensive treatment regimen, had experienced many treatment side effects and had been feeling 'down and waking up during the night with worries'. He spoke of how oncologists tended to focus 'purely on the clinical' while he wanted them to 'explore responses a bit more'.

they emphasised the clinical purpose of their relationship with oncologists and deprecated anything that diverted from this. Parents remarked on further aspects of oncologists' behaviour that were central to their comforting role and additional to their instrumental expertise, particularly their calmness and constancy.

Theorising why oncologists' communication is comforting in the absence of explicit emotionality. While communication research and training has emphasised the importance of explicit emotional discussion in supporting patients, our findings point to the value of oncologists' expert instrumental focus and the biomedical information they gave, both of which were deeply emotional in their effects on parents. In the profoundly emotional context of childhood cancer, the composed, unemotional behaviour of oncologists may provide a form of emotional support that helps to prevent parents becoming engulfed by fear and supports their core task of parenting their child through the arduous and lengthy treatment. Assumptions that emotional regulation is best achieved by overt expression and discussion of emotions - and that not engaging in such discussion is necessarily maladaptive - have been questioned in the scientific literature on emotional support. This literature points to situations in which emotional expression can even be harmful (Kennedy-Moore and Watson, 2001). Evidence further indicates that healthy adaptation is linked to the flexible expression or suppression of emotion according to the context (Westphal et al, 2010). This evidence resonates with our finding that parents preferred to discuss their emotions with specialist nurses or personal contacts rather than with oncologists. Also important here is the literature on how individuals interpret other peoples' attempts at emotional support. An individual is more likely to regard support as genuine and helpful if it is provided by someone they perceive as socially similar, whereas if the provider is perceived as socially dissimilar (e.g., an authority figure) support may be experienced as controlling or insincere (Thoits, 1986).

Implications. Our study indicates the need to review clinical communication guidance about how emotional support is provided and received. Such a review is also necessary because, although communication training tends to produce improvements' that communication experts value, evidence for its effectiveness when assessed from patients' perspectives is mixed (Shilling et al, 2003; Lobb et al, 2004; Uitterhoeve et al, 2010; Tulsky et al, 2011; Johnson et al, 2013). Oncologists in our study allocated considerable time to explaining instrumental aspects of care and this was a crucial source of comfort for many parents. However, in communication guidance and training, instrumentality is sometimes regarded as disrupting emotional discussion and diverting the consultation from patients' needs. Our and others' findings (Pedersen, 2009) suggest that the sharp distinction between instrumental and emotional communication that underlies such assumptions is unhelpful. Only two parents in our study wanted to discuss their emotions with oncologists. For parents like these, oncologists may need to identify and explicitly resolve the possible divergence between their usual approach and parents' needs.

Strengths and limitations. We designed our study to take account of something that is increasingly recognised in clinical research generally but often still neglected in clinical communication research: what matters is not necessarily what researchers or experts prioritise but what patients (or their families) prioritise. Our inductive approach and simultaneous study of both consultation and parent interview data provide insights that are absent from much of the evidence that underpins clinical communication guidance. Without data like ours, communication guidance may reflect the perspectives of researchers rather than those of patients and their families.

However, our study does have some limitations. First, we did not record the consultations that occurred within the first few days of diagnosis, as it was considered unethical to invite parents to 
participate at this time. Overt emotional discussion may be more common and important in these initial 'bad news' consultations. Nevertheless, we interviewed parents about their experiences of these consultations and our sample included consultations where oncologists gave test results that parents regarded as 'bad news'. Additionally, our longitudinal approach allowed us to explore parents' views after completion of the most difficult parts of their child's treatment when they were more able to reflect critically on their experiences. Second, we studied parent-oncologist communication about the care of children. Parents are not patients, and our findings may not be transferable to adult patient-oncologist communication, although evidence indicates that overt emotional discussion is similarly infrequent in other cancer care contexts (Pollak et al, 2007; Hack et al, 2010; Rodriguez et al, 2010). Moreover, parents' accounts in the present study converged with previous qualitative studies of adult cancer patients (Thomsen et al, 2007; Goldman et al, 2009). Nevertheless, further inductive research is needed to explore how comfort is transacted between oncologists and patients in other cancer care contexts, including those where prognosis is less favourable. Such research will show whether processes in these contexts resemble those that we report here.

\section{CONCLUSION}

Parents were usually comforted by the ways oncologists communicated. However, although cancer care clinical communication guidelines and training emphasise the role of overt emotional discussion with oncologists, most parents in our study did not want such discussion. Instead, they spoke of how they were comforted by oncologists' instrumental focus, calmness and constancy. Reflecting parents' accounts and the literature on emotional regulation, communication training and guidance may benefit from a more nuanced understanding of emotional support and the different ways that it can be provided.

\section{ACKNOWLEDGEMENTS}

We thank the participants and the staff at each of the centres for their generous help with the study. We also thank the parent and practitioner steering group representatives for their helpful contributions. This work was supported by Cancer Research UK grant number C19412/A6913. TE was funded by the Teenage Cancer Trust during this study.

\section{CONFLICT OF INTEREST}

The authors declare no conflict of interest.

\section{DISCLAIMER}

The study funder had no role in the data collection or analysis, or in the writing of the paper.

\section{ETHICAL APPROVAL}

The North West NHS Research Ethics Committee gave approval for the study (Ref. 06/MRE08/18).

\section{REFERENCES}

Beckett MK, Elliott MN, Richardson A, Mangione-Smith R (2009) Outpatient satisfaction: the role of nominal versus perceived communication. Health Serv Res 44(5 Pt 1): 1735-1749.

Bonito A, Horowitz N, McCorkle R, Chagpar AB (2013) Do healthcare professionals discuss the emotional impact of cancer with patients? Psychooncology; e-pub ahead of print 6 March 2013; doi:10.1002/pon.3258.

Epstein RM, Street RL (2007) Patient-centred communication in cancer care: promoting healing and reducing suffering. National Cancer Institute: Bethesda.

Girgis A, Cockburn J, Butow P, Bowman D, Schofield P, Stojanovski E, D’Este C, Tattersall MH, Doran C, Turner J (2009) Improving patient emotional functioning and psychological morbidity: evaluation of a consultation skills training program for oncologists. Patient Educ Couns 77(3): 456-462.

Goldman RE, Sullivan A, Back AL, Alexander SC, Matsuyama RK, Lee SJ (2009) Patients' reflections on communication in the second-opinion hematology-oncology consultation. Patient Educ Couns 76(1): 44-50.

Hack TF, Pickles T, Ruether JD, Weir L, Bultz BD, Degner LF (2010) Behind closed doors: systematic analysis of breast cancer consultation communication and predictors of satisfaction with communication. Psychooncology 19(6): 626-636.

Johnson LA, Gorman C, Morse R, Firth M, Rushbrooke S (2013) Does communication skills training make a difference to patients' experiences of consultations in oncology and palliative care services? Eur J Cancer Care (Engl) 22(2): 202-209.

Kennedy-Moore E, Watson JC (2001) How and when does emotional expression help? Review of General Psychology 5(3): 187-212.

Kuper A, Lingard L, Levinson W (2008) Critically appraising qualitative research. BMJ 337: a1035.

Lobb EA, Butow PN, Barratt A, Meiser B, Gaff C, Young MA, Haan E, Suthers G, Gattas M, Tucker K (2004) Communication and information-giving in high-risk breast cancer consultations: influence on patient outcomes. $\mathrm{Br} J$ Cancer 90(2): 321-327.

Maguire P (1999) Improving communication with cancer patients. Eur J Cancer 35(14): 2058-2065.

Pedersen R (2009) Empirical research on empathy-A critical review. Patient Educ Couns 76: 307-322.

Pollak KI, Arnold RM, Jeffreys AS, Alexander SC, Olsen MK, Abernethy AP, Sugg Skinner C, Rodriguez KL, Tulsky JA (2007) Oncologist communication about emotion during visits with patients with advanced cancer. J Clin Oncol 25(36): 5748-5752.

Reeves S, Albert M, Kuper A, Hodges BD (2008) Why use theories in qualitative research? BMJ 337: a949.

Rodriguez KL, Bayliss N, Alexander SC, Jeffreys AS, Olsen MK, Pollak KI, Kennifer SL, Tulsky JA, Arnold RM (2010) How oncologists and their patients with advanced cancer communicate about health-related quality of life. Psychooncology 19(5): 490-499.

Salmon P, Mendick N, Young B (2011) Integrative qualitative communication analysis of consultation and patient and practitioner perspectives: towards a theory of authentic caring in clinical relationships. Patient Educ Couns 82(3): 448-454.

Salmon P, Young B (2011) Creativity in clinical communication: from communication skills to skilled communication. Med Educ 45(3): 217-226.

Shilling V, Jenkins V, Fallowfield L (2003) Factors affecting patient and clinician satisfaction with the clinical consultation: can communication skills training for clinicians improve satisfaction? Psychooncology 12(6): 599-611.

Stiefel F, Barth J, Bensing J, Fallowfield L, Jost L, Razavi D, Kiss A (2010) Communication skills training in oncology: a position paper based on a consensus meeting among European experts in 2009. Ann Oncol 21(2): 204-207.

Strauss A, Corbin J (1998) The Basics of Qualitative Research: Techniques and Procedures for Developing Grounded Theory. Sage: Thousand Oaks, CA.

Thoits PA (1986) Social support as coping assistance. J Consult Clin Psychol 54(4): 416-423.

Thomsen DK, Pedersen AF, Johansen MB, Jensen AB, Zachariae R (2007) Breast cancer patients' narratives about positive and negative communication experiences. Acta Oncol 46(7): 900-908. 
Townsend P, Phillimore P, Beattie A (1988) Health and Deprivation: Inequality and the North. Croom Helm: London, UK.

Tulsky JA, Arnold RM, Alexander SC, Olsen MK, Jeffreys AS, Rodriguez KL, Skinner CS, Farrell D, Abernethy AP, Pollak KI (2011) Enhancing communication between oncologists and patients with a computer-based training program: a randomized trial. Ann Intern Med 155(9): 593-601.

Uitterhoeve RJ, Bensing JM, Grol RP, Demulder PH, VAN Achterberg T (2010) The effect of communication skills training on patient outcomes in cancer care: a systematic review of the literature. Eur J Cancer Care (Engl) 19(4): 442-457.

Vora A, Goulden N, Wade R, Mitchell C, Hancock J, Hough R, Rowntree C, Richards S (2013) Treatment reduction for children and young adults with low-risk acute lymphoblastic leukaemia defined by minimal residual disease (UKALL 2003): a randomised controlled trial. Lancet Oncol 14(3): 199-209.

Wakefield CE, McLoone JK, Butow P, Lenthen K, Cohn RJ (2011) Parental adjustment to the completion of their child's cancer treatment. Pediatr Blood Cancer 56(4): 524-531.

Westphal M, Seivert NH, Bonanno GA (2010) Expressive flexibility. Emotion 10(1): $92-100$.

This work is published under the standard license to publish agreement. After 12 months the work will become freely available and the license terms will switch to a Creative Commons AttributionNonCommercial-Share Alike 3.0 Unported License. 